the question was one of cost, and as the first-class ores became exhausted and prices rose, the second-class ores would prove remunerative.

Colonel Parrett took an optimistic view, and referred to the vast quantities of rich ore in Australia and the Transvaal.

The president, in closing the discussion, looked forward to Australia, with its vast coalfields and easy transport, becoming the great centre of iron production.

Mr. W. G. Fearnsides, in describing the pisolitic iron ores of North Wales, showed that they were not, as formerly supposed, cilaracteristic of certain geological horizons.

A paper by Prof. J. Joly, on the distribution of radium in the rocks of the Simplon Tunnel, raised many question of great interest. From the examination of thirty-six typical samples taken from various points in the tunnel, he showed them to contain varying amounts of radium, and, taken together, they were sufficient to disturb any forecast of the temperature which under normal conditions would be encountered at the level of the tunnel. presence of radium in the sediments, in hitherto un suspected quantities, raises the question whether its presence may not be a factor in the events attending mountain building. The shifting of radium and its parent elements by denudation must be regarded as a convection of thermal energy, and result in the shifting of areas of high temperature and crust-weakness from age to age as the site of sedimentary accumulation changes.

The chief papers dealing with palæontology were by Mr. F. Raw, on the trilobite fauna of the Shineton shales and on the development of Olenus salteri; the palæontology of the North Derbyshire coalfield, by Mr. A. R. Horwood, and reports from various research committees.

The Carboniferous Zones Committee, after several years of useful work, presented its final report, but the work which has been carried on with so much vigour and success by Dr. Wheelton Hind and others, will be continued by another committee of which Dr. A. Vaughan is secretary.

The committee appointed to investigate the fossiliferous drift deposits at Kirmington and at various localities in the East Riding of Yorkshire has devoted its energies to a careful examination of the mammaliferous gravels at Bielsbeck, in the Vale of York. The deposits occupy a depression in the Keuper marls, and have accumulated in a boggy hollow on an old land surface. None of the material excavated can be assigned to the direct agency of ice, and there is no evidence available which will definitely fix its age relatively to the Glacial period.

A new section of glacial gravels in Holderness was described by Messrs. Sheppard and Stather. They are considered by the authors to represent part of the terminal moraine of the North Sea ice sheet.

The pre-Devonian beds of the Mendip Hills were reported on by a committee appointed to examine their fossil contents and their relations to a peculiar coarse, ashy conglomerate found in the neighbourhood.

Mr. Lomas described the occurrence of a remarkable bed of peat found during excavations in the Union Dock, Liverpool. The chief interest of the deposit lies in the fact that the peat is composed of marine plants encrusted with polyzoa, hydrozoa, serpulæ, and other marine organisms.

Mr. A. R. Horwood read a paper on a hitherto unnoticed section of the Amaltheus spinatus zone in the Middle Lias at Billesdon Coplow, Leicestershire, and some notes on the ancient volcanoes of Basutoland were sent by the Rev. S. S. Dornan.

A catalogue of destructive earthquakes was submitted by Prof. J. Milne. Taking only those which have done structural damage, he finds that between the years II50 and 1250 A.D. large earthquakes were very frequent, and another great increase commenced about the year 1650 , and is still in progress.

Prof. Frech in, a subsequent paper showed the part which earthquakes have played in mountain building.

Reports on the Anglesey rocks, bv Mr. E. Greenly, and on erratic blocks, by Prof. P. F. Kendall, completed the papers read before the section.

No. I975, vol. 76$]$

\section{ENGINEERING AT THE BRITISH} ASSOCIATION.

IN accordance with its usual custom, the section did not meet on the opening day until Ir.15 a.m., in order that members might have an opportunity of attending the presidential addres

The

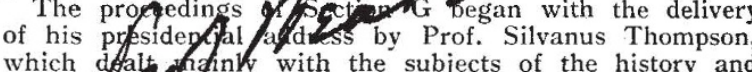
and with the subjects of the history and developherk of electric motive power, and the education and tralning engineers. After the vote of thanks to the president, Mr. Dugald Clerk read a paper on the present position of gas and petrol engines. The author pointed out that experience in the construction and design of large gas engines is gradually accumulating, but that the conditions of work in this country differ in one important respect from those on the Continent. Practically all the large Continental gas engines are operated with blastfurnace gas, while in this country producer gas has been almost exclusively used, and he was of opinion that until the problem of the bituminous fuel producer was solved, it would be difficult to continue to increase the dimensions of gas engines. Mr. Clerk himself has been working for some years now at the problem of reducing maximum pressures as well as temperatures, without reducing mean pressures, in order that the thickness of the cylinder castings, \&c., might be reduced, and that the weight of the engine itself might be made more reasonable for moderate powers; he has been experimenting with a 50 horse-power engine in order to obtain definite data as to the rates of cooling of the working fluid in the actual engine at different temperatures and pressures, and he showed a very interesting diagram illustrating his results, and a table of apparent specific heats of the working fluid at varying degrees of temperature which he had worked out from these experiments. This table showed conclusively a rapid increase of apparent specific heat with increase of temperature. From the values of the specific heat thus obtained, Mr. Clerk was able to obtain a curve of heat loss to the sides of the cylinder both for complete double strokes and for partial double strokes at the inner end of the stroke. The paper concluded with a brief discussion of some interesting points in connection with the petrol engine, and especially with the problem of the exhaust gases. The author showed by results of experiments on his own motor-car that by adjusting the carburetter he was able to reduce the percentage of $\mathrm{CO}$ in the exhaust gases very considerably.

In the afternoon the members of the section had an opportunity of visiting the works of Messrs. N. Corah and Sons, hosiery manufacturers, where they saw many examples of the most efficient and up-to-date machinery now used in the manufacture of hosiery. The works are extremely well planned, and reflect the greatest credit upon the proprietors, not only for the skill with which the machinery has been arranged and working costs kept down, but for the great attention paid to ventilation in the workrooms and to the comfort and general well-being of the employees.

Friday morning, with the exception of a short paper by Prof. B. Hopkinson and Mr. L. G. E. Morse on the gases exhausted from a petrol motor, was entirely devoted to a joint discussion with Section $\mathrm{B}$ on gaseous explosions with special reference to temperature. Prof. Hopkinson and Mr. Morse in their paper gave an account of experiments which had recently been carried out in the engineering laboratory of Cambridge University on a four-cylinder Daimler engine in order to determine the conditions under which carbon monoxide is formed in an internal-combustion motor, and the relation between the composition of the exhaust gases, the strength of the mixture, the power developed by the engine, and the thermal efficiency. These experiments showed that the curve obtained by plotting the thermal efficiency reckoned on the indicated horse-power to a base of petrol consumption had a sharply defined maximum near the point where the consumption was about $2 /$ ioth $\mathrm{lb}$. of petrol per 1000 revolutions, or at the point at which the petrol is just sufficient to be burnt by the available oxygen. The rapid increase in the per- 
centage of carbon monoxide in the exhaust gases as the petrol consumption was increased was shown very strikingly by another curve, and it was apparent that if the carburetter was set in the usual manner in order that the engine might give its maximum power, no attention being paid to petrol consumption, the exhaust was almost certain to contain large quantities of carbon monoxide.

The discussion on gaseous explosions was opened by Mr. Dugald Clerk, who showèd a part of the original apparatus used by Bunsen in his classic experiments. Mr. Dugald Clerk then briefly described his own important work in this field of research, beginning with his earlier experiments, in which the pressures reached were recorded by means of a Richard's indicator, down to his latest researches, some of which have been recently described in papers read before the Royal Society in March, x906, and before the Institution of Civil Engineers at the beginning of the present year, in which optical methods have been used for obtaining records of the variation of pressure with changes of volume and temperature in the cylinder. Dr. Boudouard, of Paris, followed Mr. Dugald Clerk, and described, with the help of blackboard sketches, the apparatus which is being employed by the committee which has been appointed by the French Government to carry out a fresh series of experiments on gaseous explosions, with the object of determining whether the numerical results obtained in the earlier experiments are trustworthy. Prof. Haber, of Carlsruhe, another wellknown worker in this subject, dealt very fully in his remarks with the subject of the variation of the specific heat of gases as the temperature of the gas is raised, and Prof. Dixon and Prof. Hopkinson, who also spoke, took up the same point. Prof. Dixon showed by a table of results obtained in his own experiments that, at any rate up to the limit of temperature to which he had at present worked, the specific heat of $\mathrm{CO}_{2}$ rose very markedly as the temperature of the gas was increased, while, on the other hand, there was very little apparent variation in the specific heat of nitrogen.

During the afternoon the section paid a visit to the British United Shoe Machinery Co.'s works; a very excellent descriptive pamphlet had been prepared in connection with this visit, which was a most enjoyable one, and enabled members to see to what an extent self-acting machinery is now used in connection with the manufacture of boots.

The section did not meet on Saturday, but many of the members spent the day in a visit to the Leicester and Swannington Railway, one of the oldest railways in the kingdom, constructed by George and Robert Stephenson; $\mathrm{Mr}$. Clement Stretton acted as conductor of the party.

Monday, as usual, was devoted to electrical papers, and the first paper taken was by Sir William Preece, on the Pupin mode of working trunk telephone lines. The author stated that he himself had pointed out in 1896 that the effect of electromagnetic induction in telephone wires was in one sense beneficial, and that Prof. Pupin had made it more beneficial in another sense, and had thus been able to reduce the weight of copper used on trunk lines and also to extend the distance to which ordinary speech is practicable. Sir William Preece inspected in April last the very successful work which has been done by the New York Telephone Co. in connection with the adoption of Prof. Pupin's methods. The Pupin coil stores up a portion of the energy, which, like a spring under pressure, is ready to react on the release of the forced condition. The size of the coils and their distance apart on the eircuit is a question of experiment; Sir John Gavey has found the best results with coils at every two miles; $\mathrm{Mr}$. Carty, on the other hand, employs them at every $1 \frac{1}{4}$ mile on a long line, and at every $\frac{3}{4}$ mile on a short line. The author termed the addition of these inductance coils "loading" the line, and he stated that the use of loaded lines is increasing rapidly. In underground cables the range of a loaded line is found in this country to be $2 \cdot 4$-times that of an unloaded one. The application of this principle to submarine cables is now under investigation, though it has not yet reached a practical stage. In concluding his paper, the author pointed out that telephone troubles in this country often arise from the fact that the subscriber is entirely ignorant of the system NO. I 975, VOL. 76] of working, and will not take the trouble to make himself familiar with it.

Sir Oliver Lodge read a short paper on tuning in wireless telegraphy, and described the system adopted in the Lodge and Muirhead wireless telegraphy stations.

Mr. J. T. Morris then read a note on an oscillographic study of low-frequency oscillating arcs. The paper collected together a number of observations which had been made both with direct and alternating current arcs, mainly with the object of studying the effect of a change in the medium in which the arc is burning, and also to examine the effect, if any, produced on the arc by the application of a transverse magnetic field. No frequencies of more than 1000 were investigated. The paper was fully illustrated by curves representing the results of the experimental investigations.

The next paper was by $\mathrm{Mr}$. Leon Gaster, on developments in electric incandescent lamps. The author stated that at the York meeting last year he had been able to show a few sample rio-volt metallic filament lamps consuming I watt per candle-power; to-day such lamps were ordinary commercial articles. A number of types of metallic lamps were shown by the author, including tantalum lamps, "Osram" lamps, in which tungsten is employed, and a lamp known as the Helion lamp. In the discussion Sir William Preece stated that he had lately equipped his own house with Osram lamps of 105 voltage, and, in order to reduce the pressure from 220 volts to the necessary 105, he had put in an alternatingcurrent transformer, but the cost of this had been more than met by the saving in the payment for current within a year, and that though he had put the lamps in in January, I906, none of them had so far needed replacement.

The business of the day concluded with a short paper by Prof. E. G. Coker descriptive of the new engineering laboratory at the City and Guilds of London Institute, Finsbury. A new wing has been added to the college, in which accommodation has been provided for an engineering laboratory, drawing offices, lecture rooms, \&c, The hydraulic section of the engineering laboratory contains a long cast-iron channel, and all the necesșary measuring tanks and other appliances; a number of hydraulic machines have been installed. The engines in the heat laboratory are all of moderate size, and in many cases have been designed with special reference to research work. This new laboratory will bring the teaching equipment at Finsbury well up to date.

Tuesdav opened with two papers on ferro-concrete, one by Mr. J. S. E. De Vesian and the other by Mr. W. Noble Twelvetrees. Both authors made extensive use of the lantern, and showed a large number of slides illustrating the kind of work for which ferro-concrete has been so far generally employed. It was interesting to find that this method of construction is now rapidly making its way in this country; Mr. De Vesian showed in his lantern-slides a number of big mills, granaries, \&c., which have recently been built in Great Britain on the Hennebique system of ferro-concrete. In the first portion of his paper this author went fully into the specifications which he uses in connection with the materials required in ferroconcrete construction, and explained the tests he carries out in connection with the Portland cement.

Mr. Noble Twelvetrees showed a series of slides to illustrate the use of reinforced concrete for such types of construction as railway sleepers, standards for overhead electric cables, \&c., and he advocated the use of concrete for preserving existing steel bridges, especially where they are liable to the corrosive effect of locomotive fumes.

Mr. Worby Beaumont followed with a paper on the origin and production of corrugation of tramway rails; he suggested various causes in explanation of this peculiar phenomenon, but, though the paper led to an interesting discussion, no: speaker was able to throw any light upon the real origin of this troublesome problem, which so often worries the tramway engineer.

Two other papers were dealt with by the section on this day, one, by Mr. H. I. Brackenbury, on modern machinery and its future developments, and the other, by Mr. C. V. Drysdale, on resistance coils and their comparison. The latter author exhibited his ingenious 
apparatus, not only at the sectional meeting, but later on in the evening at the conversazione which was held in the Leicester Museum.

Owing to the very full programme of papers, the section was.forced to meet again on Wednesday, August 7 , when four papers were discussed. The first, a short paper by Mr. J. F. Brooks, described a machine for weighing the forces on a cutting tool; the author exhibited and explained one of his machines, and the values of the forces on tools with cutting angles of $65^{\circ}$ and $70^{\circ}$ when cutting cast-iron and mild stecl with small cuts at moderate speed were shown by means of diagrams.

Mr. R. S. Ball, in his paper on the governing of hydraulic turbines, dealt with the problems involved in the speed control of hydraulic turbines for a wide range of head. He showed that such regulators may be divided into two classes:-(r) disengagement governors (mechanical), which come into action when an assigned departure from the normal speed is attained, being otherwise out of gear; (2) continuous governors (mechanical and hydraulic), which are always connected to the gatecontrolling mechanism, and which begin to operate at the moment the speed rises or falls from the normal. The action of various types of governors was described by figures and diagrams plotted from the results of tests.

Frof. H. T. Barnes, of McGill University, Montreal, then read a paper on the ice problem in engineering work in Canada. He showed that in Canada there is always great steadiness of the temperature of the water throughout the ice season, and that there are three varieties of ice to be distinguished-surface or sheet ice, spicular or frazil ice, and anchor or ground ice. Prof. Barnes explained that by an intelligent use of artificial heat, especially at night time, when super-cooling is most common, the interference of ice with the normal operation of a power-house may be largely prevented. The most favourable condition for a power-house is when it is situated on a river normally frozen over on its surface and with no stretches of open water above.

The section concluded its business with the reading of some notes' by Mr.' J. 'Smyth on the application of waterpower and how to secure the greatest efficiency in working same,

\section{UNIVERSITY AND EDUCATIONAL INTE LLIGENCE.}

THE sum of 50 poo dollars has been appropriated by the Kansas Legiofatyre for the erection of engineering buildings in connetrom with the State university.

The Sunderland Technical College is to be extended by the addition of pday training college and engineering laboratories at froposed cost of ro,oool.

Dr. JAimes E. Talmage has resigned the professorship of geology in the University of Utah in order to devote himself to inves/sation work in mining geology. Dr. F. J. Pack has ween appointed to succeed him.

THIs year's scholarship of the Institution of Naval Architects has been awarded to Mr. A.' M. Robb, Glasgow. The scholarship the annual value of 5 ol., and, subject to the regulations, is tenable for three years.

Mr. Simon Flexiner has been made a member of the Rockefeller Institute for Medical Research, New York, and director of the pathological laboratories; and the following have befppointed members of the institute :Mr. S. J. Melt $r$ (physiology and pharmacology), Mr. E. L. Opie (pathology), and Mr. P. A. Levene (biological chemistry).

ThE calendar of the Manchester School of Technology and Municipal School of Art for the session 1907-8 has just been issued by the firm of John Heywood, Ltd. In it are to be found particulars of the courses of instruction, and the sclolerships, prizes, \&c., at the institution. Many of the laboratories and workshops are pictorially represented in the volume.

THE following appointments abroad have recently been made :- - at the Rush Medical College, Chicago, Dr. Robert R. Bensle fo be professor of anatomy, and Dr. No. [975, voL. 76 ]
Edwin O. Jordan professor of pathological anatomy and bacteriology; Dr. Francis Huber has been elected to the chair of medicine at the New York College of Physicians and Surgeons, and Dr. Frederick Peterson to that of psychiatry in the same institution; at Yale University, Dr. J. M. Flint has been appointed professor of surgery at Würzburg, Dr. Faust has been made professor of pinarmacology.

THE remarkate progress accomplished by the Japanese during the last thirty-two years in the field of public education is brought out very clearly in the thirty-second anneal report of the Japanese Minister of Public Instruction, which has been published recently. This report deals with the year 1904-5, the date of the war with Russia. It is instructive to note that this time of stress was allowed to interfere in no way with educational activity. The Emperor, indeed, proclaimed it to be a national duty The emperor and efforts of educational administrators and teachers should be redoubled. Despite the financial difficulties to which a great war gave rise, the expenditure on education was not diminished. While in 1873 only twenty-eight out of every 100 children were under instruction in public schools, the ratio had risen in the year under review to the remarkable one of 97 boys and $9 \mathrm{I} \cdot 5$ girls out of every hundred, and the number of children in the schools had reached $7,55^{1}, 445$. Higher education, too, was in an equally flourishing condition. For example, the number of students in the University of Tokyo had reached 3500 , and in Kioto 1300 . Numerous special schools, technical schools for engineers and for agricultural specialists, medical schools, and schools for the study of modern languages, were all in a high state of efficiency. Moreover, a point of special interest in our country to-day, the hygiene of schools, is scrupulously watched, and medical officers are charged specially with the duty of keeping the pupils under examination. Allogether the report provides abundant evidence of the success with which Japan is educating her people.

\section{SOCIETIES AND ACADEMIES. LONDON.}

Royal Society, June 6.- "The Osmotic Pressure of Compressible Solutions of any Degree of Concentration." By Alfred W, Porter.

An exact equation is obtained connecting osmotic pressure with the vapour pressures of solvent and solution, viz. :-

$$
\int_{\pi_{\pi}}^{p} s d p+\int_{p-\mathrm{P}_{p}}^{\pi_{00}} u d p=\int_{\pi_{\pi}}^{\pi_{00}} v d p,
$$

where

$\mathrm{P}_{p}$ is the osmotic pressure when the hydrostatic pressure of solution is $p$;

$\pi_{00}$ is the vapour pressure of the solvent when under the hydrostatic pressure of its vapour alone :

$\pi_{\pi}$ is the vapour pressure of the solution when under the hydrostatic pressure of its vapour alone.

$v$ and $u$ are the specific volumes of vapour and solvent; $s$ is the diminution of a very large volume of the solution when I gram of solvent is removed.

The equations given by van 't Hoff and the Earl of Berkeley can at once be derived from this general one by taking the liquids as incompressible and considering respectively the cases in which (I) the solvent, (2) the solution, is under the pressure of its own vapour alone.

It is shown that if two solutions in the same solvent have the same osmotic pressure, they have also the same vapour pressure provided the values of these pressures be measured for the same hydrostatic pressure of the solution. They have also the same freezing point.

It is shown that when a solution is in equilibrium with the pure solvent across a semi-permeable membrane the vapour pressure of the solution is necessarily equal to the vapour pressure of the solvent, each being measured for the actual hydrostatic pressure of the fluid to which it refers. 